\title{
Supply Chain in Electro-Energetics and Real Options
}

\section{O. Drahovzal}

This paper deals with determining the value of the connection in the supply chain in electro-energetics. First, useful connection options are described. The principle of deviations in the energetic system is then briefly described, and examples of their histories are shown in a chart. Next methods for evaluating the acquisition of a connection with the producer of electricity are explained. The simple classical approach to the problem and the real options approach are described. The real options approach is considered to be the most correct, providing the most realistic results. Then there is an example of a calculation for a company, and certain values for the prices of deviations are calculated and shown. Finally, a comparison of the results is made, and their consequences for the decision process are explained.

Keywords: Supply chain, deviations, real options.

\section{Connections in supply chains (vertical diversifications)}

The connections options are not numerous, because the supply chain in electro-energetics is relatively short - producer, (transmission system), (distribution system), customer. The systems in parenthesis can be bypassed. This paper deals with the view of the market for the electricity distribution company (this does not refer to distribution of electricity, but to the part of the company that trades with electricity). The only real way for connection is with the producer. In the calculations below, a simplificaiton will be made, and a short-term diagram of supply only will be presented. This refers to the differences between main part of diagram, covered by standard purchases, made in advance on the standard market for electricity, and the prediction of consumption, which is made not more than one day in advance. In the conditions in the Czech Republic it is not possible to buy a producer, who is able to cover the whole diagram of all its customers. A connection with producer could be made using the following options:

- Buy a production capacity (an existing facility or a newly-built facility). This is barely feasible (if the producer or facility is big enough, it will be very expensive, and if the producer is small, the impact will be minimal - the purchase depends very much on the price).

- Connect with an existing producer trough a contract (i.e., buy or rent an exact part of its production capacity, or pay for rights to use this capacity freely).

The second variant was chosen for the explanation. Before attempting to determine the value of the connection, it is important to take into account what might occur during cooperation with producer, and the principle underlying the cooperation:

1) Prediction of consumption is higher than the amount of electricity purchased $\Rightarrow$ production of the source can be increased, or production can be started (substitution of negative deviation by the costs for the electricity produced).

2) Prediction of consumption is lower than the amount of electricity purchased $\Rightarrow$ production of the source can be decreased or stopped (substitution of positive deviation by the costs for non-produced electricity).
It is clear, that the designation of predicting the price of the deviations will play a very important role in the evaluation.

\section{Deviations}

The market operator in the Czech Republic performs the so-called settlement of deviations. The operator determines the balance between the purchased / sold and the actually consumed / supplied electricity for each participant in the market and for the system as a whole. The price of the deviations depends on the state of the system at the given moment and also on the price of the auxilliary services that had to be activated. A negative deviation from the distribution system point of view means that more electricity was taken from the transmission system than was purchased, while a positive deviation means that less electricity was taken from the transmission system than was purchased. From the producer's point of view, a negative deviation means that less electricity was supplied to the transmission system than was sold, and a positive deviation means that more electricity was supplied to the transmission system than was sold. The price of the deviations does not always have to be positive (company has to pay), but can be negative as well (company will be paid) in cases when the deviation of the company is opposite to the deviation of the whole system. This means that the deviation of the system is being improved by the deviation of the com-

Price of negative deviations on the day of the annual maximum (November $28^{\text {th }}$ ), minimum (August $7^{\text {th }}$ ) and January $1^{\text {st }}$

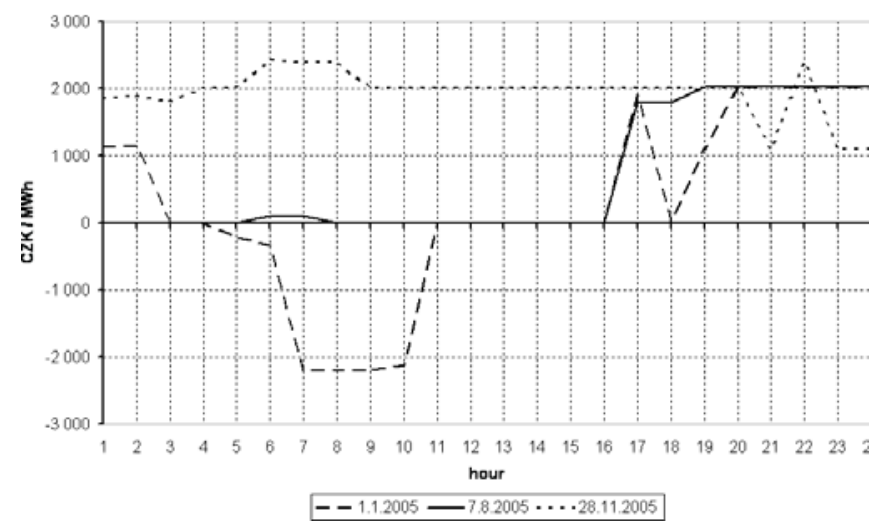

Fig. 1: Prices of negative deviations 


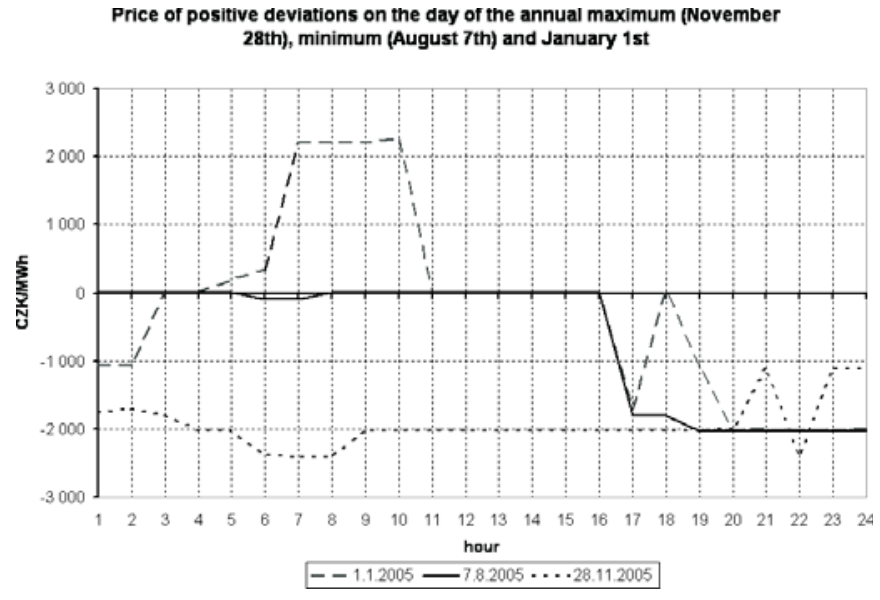

Fig. 2: Prices of positive deviations

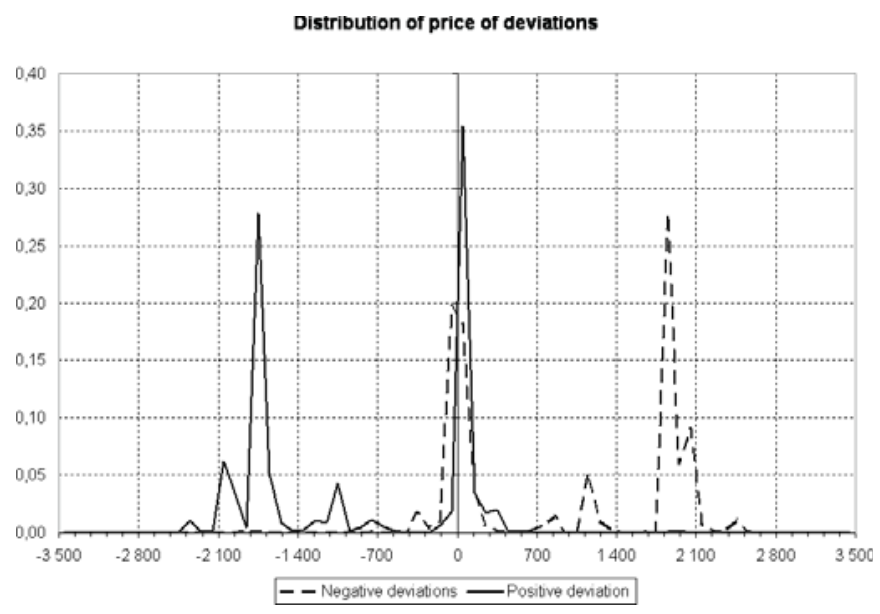

Fig. 3. Distribution of deviations

pany. The following graphs show big changes in the deviation prices and the distribution.

\section{Determining the value of a connection}

The principle is to determine acquisitions (revenues costs) of one megawatthour obtained by connection with the producer - only the covering of negative deviations will be calculated. For simplification, the selling price of one megawatthour was set as fixed and known in advance. The two main variables entering the equation are the price of the deviation and the price for the electricity from the producer (only unary single tariff for electricity - payments for the energy and not for the capacity only - is assumed in this paper).

\subsection{Evaluation by standard methods}

The principle is to calculate the difference between revenue and loss. Assuming that we know or can easily predict the price for the supplied electricity, the only problem is to determine the price of the deviation. The first option is to predict the price as the average value of historical values (which can be pertinently heightened with the trend):

$$
P=\frac{\sum_{t=1}^{n} C_{t}^{0}}{n}-C_{\mathrm{E}},
$$

where $C_{t}^{0}$ is the price of a deviation in a given period of time, $n$ is the number of time sections, and $C_{\mathrm{E}}$ is the price for the supplied or non-supplied electricity. This approach is very simple, but also provides the most inaccurate results.

The second option is to predict the price of the deviations as the median of the historical values:

$$
P=C_{\mathrm{M}}^{0}-C_{\mathrm{E}},
$$

where $C_{\mathrm{M}}^{0}$ is the median of the price of the deviations. This approach is also very simple, and its results are very dependent on the distribution of the prices of the deviations.

\subsection{Evaluation by real options}

The principle of the following equation uses the option to switch, which is computed as the sum of two options. The first is the put option, with the following parameters: the current price is the present value of the future cash flows with input $\# 1$, the strike price is the variable costs with input \#1, time to expiration is the lifetime of the project, and the volatility of the asset price is the volatility of the future cash flows with input \# 1. The second option is the call option with the same parameters as the put option expect that input \#1 is changed to input \#2. The Black-Scholes formulas for standard European call and put options have the following form:

$$
\begin{aligned}
& C=S \cdot N\left(d_{1}\right)-X \cdot \mathrm{e}^{-r t} \cdot N\left(d_{2}\right) \\
& P=-S \cdot N\left(-d_{1}\right)+X \cdot \mathrm{e}^{-r t} \cdot N\left(-d_{2}\right) \\
& d_{1}=\frac{\ln \left(\frac{S}{X}\right)+\left(r+\frac{\sigma^{2}}{2}\right) \cdot t}{\sigma \cdot \sqrt{t}} \\
& d_{2}=d_{1}-\sigma \cdot \sqrt{t}=\frac{\ln \left(\frac{S}{X}\right)+\left(r-\frac{\sigma^{2}}{2}\right) \cdot t}{\sigma \cdot \sqrt{t}},
\end{aligned}
$$

where $S$ is the current value of the asset, $X$ is the strike price of the asset, $N()$ is the standard normal cumulative distribution function, $r$ is the risk-free interest rate, $t$ is time to expiration of the option, and $\sigma$ is the volatility of the price of the asset. The formula for calculating the value of the option to switch then has the following form:

$$
V=P+C
$$

and the formula for calculating the total value of a connection has the following form:

$$
V_{\mathrm{T}}=V+\frac{\sum_{t=1}^{n} C_{t}^{0}}{n}-C_{\mathrm{E}} .
$$

This approach is the most correct, it includes a calculation of the great volatility and instability of the price of the deviations and gives the best and most accurate results. 


\section{Solution and results}

The company PRE (Pražská energetika, a.s.) was chosen for evaluation. Data was extracted from the annual report, which was downloaded from the company website. Data on deviations and their prices was obtained from the website of the market operator. The results are shown in the following graph:

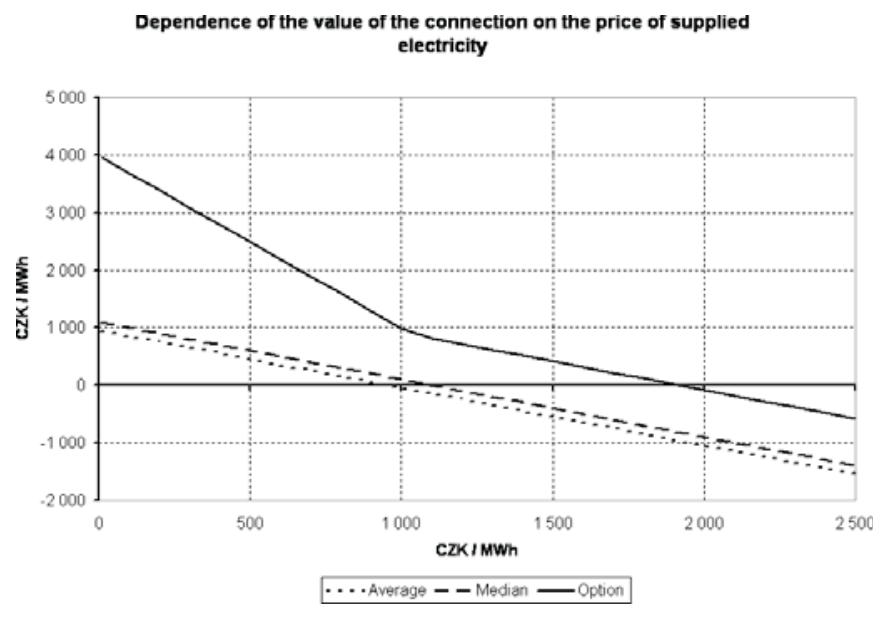

Fig. 4: Value of the connection

Numerical results that are show the point where the decision changes (the maximum price, at which the acquisition is equal to zero), are shown in the following table:

Table 1: Numerical results

\begin{tabular}{|c|r|}
\hline Average & 959.06 \\
\hline Median & 1103.98 \\
\hline Option & 1918.12 \\
\hline
\end{tabular}

If the total value of the connection is being calculated, the sum of the options for each hour should be used. If the contract has a life time of one year, the company can use the producer in each hour in this year, which means 8760 hours. Thus the total value is the sum of 8760 options to switch. For example, if the price for one megawathour will be $1500 \mathrm{CZK}$, which is very high, the total value of the project, which allows the company to control one megawatthour of the producer for one year, is about 3 millions CZK.

\section{Conclusions}

It is logical that the determining the connection acquisition has a big influence on the decision-making process. The calculations show that the use of standard methods gives results that exclude the connection of the distribution company with the producer of the electricity, because the profitable price for the supplied electricity comes out too low. On the other hand, evaluation by real options gives totally different results, due to the very great volatility of the price of the deviations, and shows the connection in a completely different light. This paper, for the purposes of illustration, simplifies the input parameters. It could be interesting for future research to focus, for example, on the multi-component price of electricity or to perform a more sophisticated exploration of a longer history of prices of deviations.

\section{Acknowledgments}

This research was financially supported by Research Project MSM6840770017 of the Czech Ministry of Education, Youth and Sports.

\section{References}

[1] Scholleová, H.: Real Options. Dissertation thesis, Prague, 2004.

[2] OTE (Market operator in Czech Republic), [online] www.ote-cr.cz.

[3] ERU (Energy regulatory office), [online] www.eru.cz

[4] CEPS (Company operating Transmission System), [online] www.ceps.cz.

[5] PRE (Prague distribution company), [online] www.pre.cz

Ing. Ota Drahovzal

e-mail:drahovo@feld.cvut.cz

Department of Economics, Management and Humanities

Czech Technical University in Prague

Faculty of Electrical Engineering

Technická 2

16627 Praha 6, Czech Republic 